\title{
DIVERSITY: FORTUNE OR MISFORTUNE?
}

Anthropologically, Indonesia is rich of diversities. It occupies the largest ethnic groups of the world. On the one hand, diversity is viewed as wealth, pride and goal for other countries to learn tolerance. On the other hand, it is actually latent potentials for national disintegration.

The pride is at stake. Diversity serves as a political commodity to gain power. People are falsified, manipulated and deceived by power-seekers thoughtlessly. A valuable lesson from a country that once had similar wealth with similar issues does not seem to be a major reference. Learning from something bad is easier than that is good like the way to hell is easier than the way to heaven.

Nowadays, we can see the growing seeds of disintegration at many places. Seemingly, people are easily disunited and ironically social media does not play positive role to unite the people. Instead, they tend to exacerbate discrimination and hate speech. The jargon "NKRI harga mati" is superficially understood. Even, I am Indonesian I am Pancasila strongly sounded contains many conceptual problems. It seems that this country does not need jargon, slogan or the like but a remedy that can awaken the deepest consciousness that the diversity is a fortune not misfortune.

The second stage of regional elections has been conducted by bringing up diversity issue as political commodity which is proven successful to gain power. The next election will be next year with similar pattern. The problem is whether the old wound experienced in particular areas will also appear in other areas. In this regards, we do not only set out normative selection procedures as determined by the electorate but also prepare for psychological shock caused by the friction that exploits diversity as political commodity. We expect that the regional elections, presidential election and legislative election do not trigger national disintegration or anything against the ideals of nation, rather, it builds a nation that uphold tolerance for diversities and differences.

Purwokerto, May 2017

Editor in Chief

Agus Raharjo 